Ian D. Watson*, Joanna Siodmiak, Wytze P. Oosterhuis, Joel Corberand, Per E. Jorgensen, Zeliha Gunnur Dikmen, Snezana Jovicic and Elvar Theodorsson, for the EFLM Working Group on Patient Focused Laboratory Medicine

\title{
European views on patients directly obtaining their laboratory test results
}

DOI 10.1515/cclm-2015-0056

Received January 17, 2015; accepted April 16, 2015; previously published online June 3, 2015

\section{Abstract}

Background: Medicine is a highly professionalized endeavour, by tradition centred on the authority of physicians. Better education and the advent of the information age cater for increased demands on society in general and on health care in particular to enable people to make informed decisions regarding themselves. Participation in medical decisions requires informed knowledge which is hard to obtain without substantial and time consuming professional help.

Methods: We performed a survey amongst the member organizations of European Federation of Clinical Chemistry and Laboratory Medicine (EFLM) in order to investigate the recognition and preparedness of providing help to patients in interpreting their laboratory results.

Results: Out of 40 EFLM Member Societies, 27 sent their responses to the survey. In most cases the first line delivery of laboratory results to physicians is by computer link $(63 \%)$. Patients receive their laboratory results on demand

*Corresponding author: Ian D. Watson, c/o European Federation of Clinical Chemistry and Laboratory Medicine, Via Carlo Farini 81, 20159 Milan, Italy, E-mail: idw@liv.ac.uk. http://orcid.org/0000-0003-2294-3715

Joanna Siodmiak: Faculty of Pharmacy, Department of Laboratory Medicine, Collegium Medicum in Bydgoszcz, Nicolaus Copernicus University in Torun, Bydgoszcz, Poland

Wytze P. Oosterhuis: Atrium-Orbis, Department of Clinical Chemistry and Haematology, Heerlen, The Netherlands

Joel Corberand: Faculty of Medicine, University Hospital Toulouse, Rangueil, France

Per E. Jorgensen: Hospital Management, University Hospital of Copenhagen, Glostrup Hospital, Glostrup, Denmark

Zeliha Gunnur Dikmen: Faculty of Medicine, Hacettepe University, Department of Biochemistry, Ankara, Turkey

Snezana Jovicic: Center for Medical Biochemistry, Clinical Center of Serbia, and Department for Medical Biochemistry, Faculty of Pharmacy, University of Belgrade, Belgrade, Serbia

Elvar Theodorsson: Department of Clinical Chemistry, University Hospital, Linköping, Sweden from their physician in $60 \%$ of cases. However, $34 \%$ of laboratory specialists showed a negative attitude for delivering laboratory results to patients. Yet, in $48 \%$ of countries 1-5 patients per day ask a laboratory specialist about the significance of laboratory results outside the reference range. When patients are informed about the purpose of laboratory testing, they seek information primarily from their physician, followed by the internet and the Specialist in Laboratory Medicine.

Conclusions: Changing practices increasingly enabling patient access to their records are on the increase facilitated by recent innovations in information technologies. Successful transfer of some of the responsibilities of physicians, demands a mutual triangular dialogue between the patient, their physician and laboratory medicine.

Keywords: laboratory medicine; laboratory results; interpretation; patient focused.

\section{Introduction}

There is a decisive move towards a patient-centred approach to medicine including increased patient independence and involvement [1]. Laboratory medicine is a key element in the diagnosis, monitoring and intervention of patients; currently this contribution to patient care is almost exclusively through their physician. However, an increasing body of evidence shows that empowering patients in their own health care has a positive impact; in the realm of laboratory medicine this may, e.g., be exemplified by the widespread acceptance of self-monitoring of blood glucose [2] and INR [3] which even include measurable economic benefits [4].

Countries differ in how patients access their patient records including laboratory results and how they receive corresponding information including interpretation. For several patients suffering from chronic diseases there is a crucial ongoing need for monitoring treatment progress using laboratory test results. Such patients are often motivated to engage in managing their condition, indeed may 
extend that engagement to their family and carers. While accepting that literacy, numeracy, intelligence and other factors will determine to what extent patients may be able to engage [5], it is true that most have the inherent ability to do so; some of this is aided by the way such data is presented $[6,7]$.

However, the model of medical paternalism is changing, with increasing recognition that patients need to be engaged in their care, including access to their medical records, also including the results of laboratory-, imagingand other investigations [8]. There is increasing expectation that this will be so and indeed in some cases enacted or about to be $[9,10]$; in other jurisdictions patients present to laboratories and provide their results for their physician to consider. In all these scenarios there is an expectation that the clinician will provide the necessary advice and interpretation to the patient. However, if there is an increasing expectation from patients, as seen with access to internet diagnostics [11], then there will be an increased burden on front-line physicians; there is therefore a role needing fulfilled to provide appropriate contextual interpretations to patients; if this is so are specialists in laboratory medicine willing or able to take on such a role?

The aim of this study was to get a perception on laboratory professionals' views to delivering laboratory results directly to patients, as well as to perceive the current status of these issues in Europe. We report the results of a survey based on responses received from member associations of the European Federation of Clinical Chemistry and Laboratory Medicine (EFLM) to assess recognition of such an eventuality.

\section{Materials and methods}

A questionnaire was prepared by the EFLM Working Group on Patient Focused Laboratory Medicine (WG-PFLM) (see Appendix) and distributed to all member societies $(n=40)$, responses were confirmed through the EFLM member association National Representatives to confirm they were a reasonable reflection of current practice and views in that country.

Where more than one response was received from a country a median response was derived.

\section{Results}

Responses were received from 27 countries (68\%). Countries that took a part in the project were France, Belgium, Turkey, UK, Poland, The Netherlands, Serbia, Sweden, Norway, Ukraine, Albania, Croatia, Slovakia, Lithuania,
Bosnia and Herzegovina, Ireland, Russian Federation, Italy, Slovenia, Germany, Iceland, Spain, Switzerland, Greece, Montenegro, Finland, and Austria. Results of the study show that in most cases the first-line delivery of laboratory results to physicians is by computer link (63\%), patients bringing the results (21\%), e-mail (13\%) followed by fax (2\%) and ordinary mail (1\%); the most frequent secondary and tertiary transmission through these modes were e-mail (42\%) and fax (38\%), respectively.

In $60 \%$ of cases, patients received their laboratory result from physicians only after asking for them, but this was not allowed for $16 \%$ or it was allowed only in special occasions $(24 \%)$.

The survey suggested that 1-5 patients per day ask laboratory specialists about the significance of laboratory results outside the reference range. This was noted in $48 \%$ of cases.

There is some legislation or regulations in $89 \%$ of countries on whether patients can receive their results; in more than a half of the analyzed countries there are no legal impediments to delivering and interpreting laboratory results to patients; but in some cases the laboratory specialists did not know if there were restrictions. Of laboratory specialists $34 \%$ showed a negative attitude with the need to deliver laboratory results to patients.

Clinical interpretative comments added by a specialist in laboratory medicine to the report for physicians can be seen by the majority of patients. Unqualified access to unmodified comments were enabled in $49 \%$, but not allowed in $24 \%$ of respondent countries, the remainder had varying qualified access (Figure 1).

An integral part of some chronic disease monitoring is laboratory testing, yet only a small majority of patients $(54 \%)$ are made aware of this fact (Figure 2).

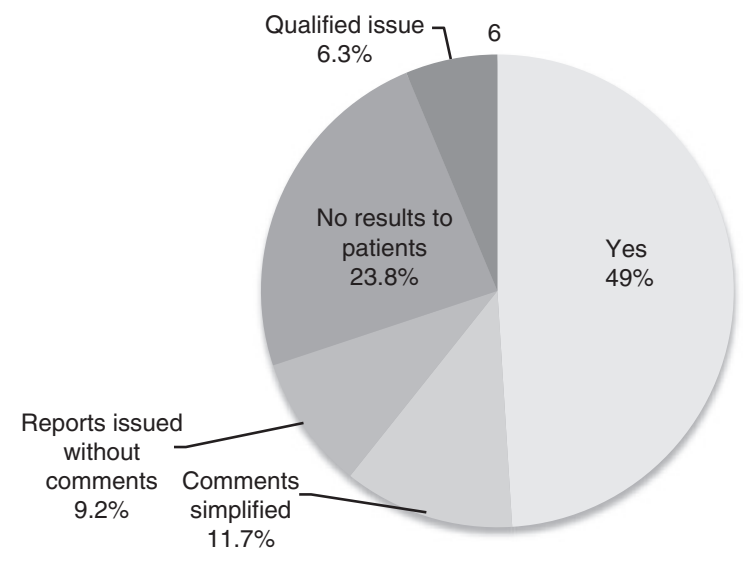

Figure 1: Availability of clinical interpretative comments added to laboratory test results intended to medical professionals to patients, with and without modification. 


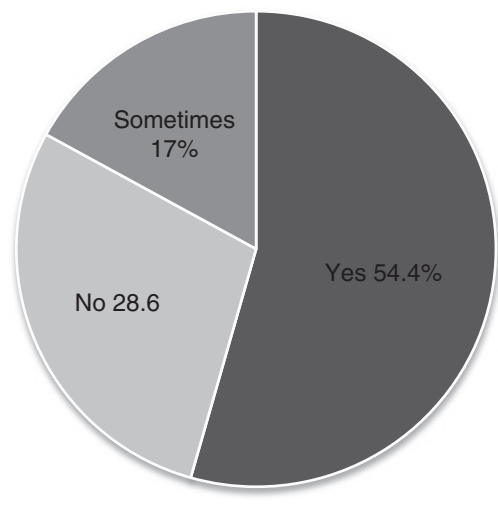

Figure 2: Are European patients informed about the laboratory tests used for their chronic disease monitoring?

When patients have been informed of why tests were done there was equal interest between those with acute and chronic presentations. Patients seek information from a number of sources. Their prime sources are their physician, the internet and the specialist in laboratory medicine (Table 1).

The willingness of EFLM societies to provide results are shown in Table 2.

\section{Discussion}

Changing perspectives enabling patient access to their records, i.e., access to 'open notes', is on the increase [12]. Innovations such as My Chart [9] have already proven popular in the USA, and in Denmark patients have access to their own medical record from hospitals including laboratory results [13]. There is a recognized need for interpretation of results to individualize results beyond the quality generic information available from an authoritative site, such as Lab Test on Line [11] and the majority of Laboratory Medicine Societies surveyed are supportive of an approach that enables better patient engagement and comprehension. If there are legal and ethical impediments $[14,15]$, that is a matter for national governments; for EU countries health is a subsidiarity matter, though crossborder health policy initiatives would be facilitated with patient ownership of their record, including results [16].

Table 1: Percent of answers on patients' sources of information (more than one response was possible).

\begin{tabular}{lrrrr}
\hline $\begin{array}{l}\text { Their } \\
\text { physician }\end{array}$ & Internet & $\begin{array}{r}\text { Specialist in } \\
\text { laboratory medicine }\end{array}$ & $\begin{array}{r}\text { Rarely } \\
\text { ask }\end{array}$ & Other \\
\hline 94 & 64 & 46 & 19 & 3 \\
\hline
\end{tabular}

Table 2: EFLM member societies willingness (in percentages) to provide more information and interpretation in collaboration with the patient's physician directly to patients.

\begin{tabular}{lrrr}
\hline Support of EFLM Societies to: & Yes & No & $\begin{array}{r}\text { With } \\
\text { reservations }\end{array}$ \\
\hline $\begin{array}{l}\text { Provide more information directly to } \\
\text { patients }\end{array}$ & 47 & 34 & 19 \\
$\begin{array}{l}\text { Interpretation of results directly to patients } \\
\text { in agreement with the patient's physician }\end{array}$ & 46 & 41 & 13 \\
\hline
\end{tabular}

Patients want to know about results [17]. In a UK study patients complained of the way results were communicated by administrative staff and the lack of direct health professional engagement [18]. Better communications with patients may enable better use of tests [19]; such an approach fits well with advocated models of integrated care. There is no doubt that patients run a substantial risk of misunderstanding medical information [20] and that there are patient-specific factors that affect comprehension [21]. The main patient-specific factor for laboratory medicine is numeracy [5], this may be addressed by the use of graphs and pictograms $[6,7]$.

Provision of access to their data requires a patient to have a thorough understanding of the information presented and even improved communication skills [19].

Providing patients with access to their personal health record apart from creating a new health environment for the patient also brings responsibilities for them, particularly social, but also legal and ethical issues [14]. The obligations consequent on the digital revolution also has emotional impact, forcing the patient to confront their illness possibly in the absence of the emotional support, which used to be provided by face-to-face interaction, possibly over extended periods of time [22].

The research in the area of communicating results, while acknowledging the benefits to patients and their engagement, needs to be more progressive with active patient involvement in such research and the implementation of technological communication options [23]. Contrary to expectation, web-based interventions to aid self-monitoring was found to be sub-optimal, yet telephone prompting, i.e., personal contact, improved behaviors [24].

The concept that specialists in laboratory medicine take on the role of laboratory result partner and communicator is not unique, Radiologists are having the same thoughts $[25,26]$. Such an approach would require modern and well functioning information technologies. If successful this would transfer some of the burden from physicians, particularly those in primary care; clearly there needs to be a triangular dialogue between the 
patient, their physician and the clinical support activities, such as radiology and laboratory medicine. Evidently patients expect this to be approached from the perspective of mutuality [27, 28].

This is a potential paradigm shift in laboratory relationships with patients and physicians and there appears to be an appetite for such progress as exemplified by a recent opinion piece in a leading medical journal [29]. We intend to encourage the approaches identified in this paper as advocates and practitioners; we hope many feel enabled and enthused to do the same.

Author contributions: All the authors have accepted responsibility for the entire content of this submitted manuscript and approved submission.

Financial support: None declared.

Employment or leadership: None declared.

Honorarium: None declared.

Competing interests: The funding organization(s) played no role in the study design; in the collection, analysis, and interpretation of data; in the writing of the report; or in the decision to submit the report for publication.

\section{Appendix}

\section{EFLM Patient Focused Laboratory Medicine Working Group}

\section{Questionnaire}

1. How are laboratory results delivered in most cases to physicians in your country? More than one answer can apply. Please rank in order of frequency:

By post

By fax

By computer link

Delivered to patients who bring them to physicians By email

2. If the results are delivered directly to the physician, can a patient collect his/her laboratory results on demand? No

Yes

Yes, in special occasions

N/A

3. From your experience is there a desire among laboratory specialists in your countryto deliver laboratory results to patients? Please make an estimation:

No

Yes $<25 \%$
Yes 25\%-50\%

Yes 50\%-75\%

Yes

No answer

4. Are there any legal issues about delivering and interpreting laboratory results to patients in your country? No

Yes

No answer

5. Do patients ask laboratory specialists about the significance of laboratory results outside the reference range and how frequently?

No

Yes $>5$ patients per day

Yes, 1-5 patients per day

No answer

6. Are clinical interpretative comments added to the results report by the laboratory professional?

Yes

No

Sometimes

No answer

7. Are the clinical interpretative comments the same for physicians and for patients?

Yes

No, for patients they are simplified

No, reports issued to patients upon their request do not contain any comments

Patients do not receive results Other (please comment)

8. Which patients usually ask about the significance of the results of requested laboratory analysis?

Chronic patients

Patients with acute problems

Both

No answer

9. Are chronic patients informed about the significance of laboratory parameters used for monitoring of their condition?

Most of the times they are

Most of the times they are not

Approximately there is the equal number of both No answer

10. Are patients allowed to request laboratory analysis on their own expense?

No

Yes

No answer

11. How do patients get information about why tests are performed? More than one answer can apply. From their physician 
Internet

Ask and from the laboratory specialist

Rarely ask

Other (please specify)

12. From your experience, if patients can get their results from the laboratory, how do they get an interpretation? More than one answer can apply. Please sort in order of frequency:

From their physician

From the laboratory specialist

From the internet

Other information service

13. How are these reports delivered to the patient? More than one answer can apply. Please rank in order of frequency:

By post/email to the patient personally

The patient must collect them personally in the laboratory

Anyone can collect them in the laboratory

The patient can specify to the laboratory who will collect report

14. Would your professional society support providing more information directly to patients?

Yes

No

No answer or comment only

15. Does your professional society support providing interpretation of results directly to patients (with the agreement of the patient's physician)?

Yes

No

No answer or comment only

16. Does your professional society support the use of self monitoring of relevant laboratory tests?

Yes

No

No answer or comment only

17. Are laboratory professionals involved in helping patients to perform self monitoring of laboratory tests?

No answer or comment only

No

Yes by: recommending good test equipment, teaching the patient how to handle the equipment, performing quality assurance of the equipment, discussing problems experienced by the patients

18. Does the clinical doctor decide at which location the blood samples are to be taken, or can the patient choose the most convenient location (e.g. the laboratory closest to their work or home)?

Yes
No

No answer or comment only

19. Highest degree:

20. Public or Private laboratory?

\section{References}

1. Dwamena F, Holmes-Rovner M, Gaulden CM, Jorgenson S, Sadigh G, Sikorskii A, et al. Interventions for providers to promote a patient-centred approach in clinical consultations. Cochrane DB Syst Rev 2012;12:CD003267.

2. Schnell O, Alawi H, Battelino T, Ceriello A, Diem P, Felton $A$, et al. Addressing schemes of self-monitoring of blood glucose in type 2 diabetes: a European perspective and expert recommendation. Diabetes Technol Ther 2011;13:959-65.

3. Heneghan C, Ward A, Perera R, Self-Monitoring Trialist Collaboration, Bankhead C, Fuller A, et al. Self-monitoring of oral anticoagulation: systematic review and meta-analysis of individual patient data. Lancet 2012;379:322-34.

4. Craig JA, Chaplin S, Jenks M. Warfarin monitoring economic evaluation of point of care self-monitoring compared to clinic settings. J Med Econ 2014;17:184-90.

5. Woloshin S, Schwartz LM. Communicating data about the benefits and harms of treatment: a randomized trial. Ann Intern Med 2011;155:87-96.

6. Fuller R, Dudley N, Blacktop J. How informed is consent? Understanding of pictorial and verbal probability information by medical inpatients. Postgrad Med J 2002;78:543-4.

7. Zikmund-Fisher BJ, Witteman HO, Dickson M, Fuhrel-Forbis A, Kahn VC, Exe NL, et al. Blocks, ovals, or people? Icon type affects risk perceptions and recall of pictographs. Med Decis Making 2014;34:443-53.

8. Fisher B. Patients' access to their electronic record: offer patients access as soon as you can. Br J Gen Pract 2013;63:E423-5.

9. MyChart. Available from: https://www.mychartweb.com/ MyChart/default.asp. Accessed 28 March, 2015.

10. UK Department of Health. Major new report on digital technology. Available from: https://www.gov.uk/government/news/majornew-report-on-digital-technology. Accessed 28 March, 2015.

11. Lab Tests Online - UK. Available from: http://www.labtestsonline.org.uk. Accessed 28 March, 2015.

12. Walker J, Darer JD, Elmore JG, Delbanco T. The road toward fully transparent medical records. N Engl J Med 2014;370:6-8.

13. Sundhedsstyrelsen. Available from: https://www.sundhed.dk/. Accessed 28 March, 2015.

14. Cushman R, Froomkin AM, Cava A, Abril P, Goodman KW. Ethical, legal and social issues for personal health records and applications. J Biomed Inform 2010;43:S51-5.

15. Vautrey R. Patients' access to their electronic record: proceed with caution. Br J Gen Pract 2013;63:327-8.

16. Kharrazi H, Chisholm R, VanNasdale D, Thompson B. Mobile personal health records: an evaluation of features and functionality. Int J Med Inform 2012;81:579-93.

17. Baldwin AS, Cvengros JA, Christensen AJ, Ishani A, Kaboli PJ. Preferences for a patient-centered role orientation: association with patient-information-seeking behavior and clinical markers of health. Ann Behav Med 2008;35:80-6. 
18. Cunningham DE, McNab D, Bowie P. Quality and safety issues highlighted by patients in the handling of laboratory test results by general practices - a qualitative study. BMC Health Serv Res 2014;14:1-16.

19. de Almeida Moura J, Costa BC, de Faria RM, Soares TF, Moura EP, Chiappelli F. Improving communication skill training in patient centered medical practice for enhancing rational use of laboratory tests: the core of bioinformation for leveraging stakeholder engagement in regulatory science. Bioinformation 2013;9:718-20.

20. Keselman A, Smith CA. A classification of errors in lay comprehension of medical documents. J Med Bioinform 2012;45:1151-63.

21. Buetow S, Kiata L, Liew T, Kenealy T, Dovey S, Elwyn G. Approaches to reducing the most important patient errors in primary health-care: patient and professional perspectives. Health Soc Care Comm 2010;18:296-303.

22. Lupton $D$. The digitally engaged patient: self-monitoring and selfcare in the digital health era. Soc Theor Health 2013;11:256-70.

23. Belanger E, Bartlett G, Dawes M, Rodriguez C, Hasson-Gidoni I. Examining the evidence of the impact of health information technology in primary care: an argument for participatory research with health professionals and patients. Int J Med Inform 2012;81:654-61.

24. Greaney ML, Sprunck-Harrild K, Bennett GG, Puleo E, Haines J, Viswanath KV, et al. Use of email and telephone prompts to increase self-monitoring in a web-based intervention: randomized controlled trial. J Med Internet Res 2012;14:76-86.

25. Lown BA, Sasson JP, Hinrichs P. Patients as partners in radiology education: an innovative approach to teaching and assessing patient-centered communication. Acad Radiol 2008;15:425-32.

26. Rubin DL. Informatics methods to enable patient-centered radiology. Acad Radiol 2009;16:524-34.

27. Gittell JH, Godfrey M, Thistlethwaite J. Interprofessional collaborative practice and relational coordination: improving healthcare through relationships. I Interprof Care 2013;27:210-3.

28. Wibe T, Helleso R, Slaughter L, Ekstedtaf M. Lay people's experiences with reading their medical record. Soc Sci Med 2011;72:1570-3.

29. O'Kane M, Freedman D, Zikmund-Fisher BJ. Can patients use test tesults effectively if they have direct access? Br Med J 2015;350:h673. 